\title{
La protección consular como derecho humano
}

\author{
Odette Martínez Pérez \\ Universidad de Oriente, Cuba \\ odette@fd.uo.edu.cu \\ Dianelis Zaldivar Valdes* \\ Universidad de Oriente, Cuba \\ dzaldivar@fd.uo.edu.cu
}

Fecha de recibido: 29 de mayo de 2015/ Fecha de aprobación: 23 de septiembre 2015

\section{Resumen}

Con el incremento del tráfico migratorio, es necesario que los Estados asuman la responsabilidad que poseen de sus ciudadanos migrantes, como grupo vulnerable en sus derechos humanos. La Convención de Viena de 1963, ya formulaba la atención consular como un derecho, lo que ha sido un criterio soste nido por la jurisprudencia internacional. Sobre una de las sentencias más representativas de al respecto, trata el siguiente trabajo.

\section{Palabras claves}

Derecho humano/ protección consular / cónsul

*Licenciada en Derecho (2004). Diplomado en Administración de Justicia (2006), en Derecho Constitucional y Administrativo (2006) y Enseñanza del Derecho (2007). Premio Nacional en trabajo científico de la Unión de Jurista de Cuba en el año 2005. Profesora de Derecho Internacional Privado en la Facultad de Derecho. Universidad de Oriente. Doctora en Ciencias Jurídicas y Máster en Derecho Constitucional y Administrativo en el 2013. Santiago de Cuba. E-mail odette@fd.uo.edu.cu. Con más de 20 artículos publicados y un libro, figurando en este último año en la "Revista Caribeña de las Ciencias Sociales", "Los derechos civiles de los extranjeros en cuba. sus garantías. comentarios a la legislación actual" y en la Revista de Sociales y Jurídicas, Número 10, Derecho y Familia, La clasificación migratoria hacia una construcción teórica.

* Licenciada en Derecho (2013). Profesora de Derecho Internacional Privado en la Facultad de Derecho. Universidad de Oriente. Con más de 10 artículos publicados, figurando en este último año en la "Revista Caribeña de las Ciencias Sociales", "Los derechos civiles de los extranjeros en cuba. sus garantías. comentarios a la legislación actual" y en la Revista de Sociales y Jurídicas, Número 10, Derecho y Familia, La clasificación migratoria hacia una construcción teórica. 
With the increment of the migratory traffic, it is necessary that the States assume the responsibility that you/they possess of their migrant citizens, as vulnerable group in their human rights. The Convention of Vienna of 1963, already formulated the consular attention as a right, what has been an approach sustained by the international jurisprudence. On one of the most representative sentences of in this respect, it treats the following work.

Human right / consular protection / consul

\section{Tabla de contenido}

Reflexiones Iniciales. I. La protección consular desde diferentes dimensiones. II. Estudio teórico de los derechos humanos como categoría científica. III. La sentencia del 3I de Marzo del 2004 del Tribunal Internacional de Justicia en el Caso Avena: fundamentos de la protección consular como derecho humano. IV. Marco constitucional para desarrollar la atención consular como derecho humano. V- Reflexiones finales. Lista de Referencias

\section{Reflexiones Iniciales}

La institución consular nace de la necesidad de proteger a los comerciantes y navegantes en países extranjeros y precede a la aparición de la diplomacia permanente. En Roma también había instituciones como la del hospitium que desempeñaba funciones similares a las del actual consulado. Asimismo, en la Edad Media se desenvuelven los consulados de una forma similar a la actual, se dice que el primer consulado medieval fue establecido por Pisa en el siglo $X$ y que en los siglos XI y XII comienzan a expandirse los consulados por todo el Mediterráneo.

Los consulares venían a ser una suerte de jueces mercantiles que desempeñaban una jurisdicción que incluso abarcaba aspectos civiles y penales. También tenían una cierta importancia en la gestión de asuntos de política internacional. Durante la formación del Estado el consulado se convierte en un órgano suyo para actuar en su nombre frente a sus propios nacionales y a las autoridades del estado huésped. 
Con establecimiento de la diplomacia permanente en el siglo XVII los consulados pierden importancia. Pero, durante la segunda mitad del siglo XVIII se empieza a recuperar el consulado como un medio útil para el desarrollo de las relaciones internacionales, lo que ha resultado vertiginoso y estable hasta la actualidad, donde han tomado vital importancia ante el incremento de los procesos de movilidad internacional de la población, que al ser impactados por el fenómeno de la globalización y al modificar sus características, causas y consecuencias en las sociedades de origen y de destino; repercuten notablemente en esferas representativas de intereses estatales como la economía, la salud, el empleo, la seguridad de las fronteras y las relaciones internacionales y cuando los Estados que regulan los movimientos internacionales de población a partir de leyes que implementan las políticas migratorias y de extranjería, recrean escenarios desfavorables para los derechos de los inmigrantes y otras categorías de extranjeros y afectan bienes jurídicos imprescindibles para el desarrollo material y espiritual de los no nacionales en las sociedades de acogida.

En los últimos tiempos los tribunales internacionales han tratado la protección consular con una nueva dimensión como derecho humano, criterio que compartimos y por ello en este trabajo se comentará la sentencia 31 de Marzo del 2004 del Tribunal Internacional de Justicia, que a nuestro juicio expone las claves de la protección consular como derecho humano, con claridad y en concordancia a la doctrina científica y que diera lugar a la Opinión Consultiva $\mathrm{n}$. 16, sobre El Derecho a la Información sobre la Asistencia Consular en el Marco de las Garantías del Debido Proceso Legal (del 01.10.1999), de la Corte Interamericana de Derechos Humanos.

\section{La protección consular desde diferentes dimensiones}

En su desarrollo histórico la protección consular ha sido definida desde diferentes posiciones:

- Como institución internacional y órgano de la Administración Pública: es una institución jurídica internacional que consiste en el establecimiento de un órgano de la administración pública del Estado (Oficina consular), específico para su actividad en el exterior, en el territorio de otro, por acuerdo de ambos, con el objeto principal de asistir y proteger a sus nacionales y posibilitarles, en la medida de lo permitido por el derecho internacional y el Estado de residencia, el ejercicio de sus derechos y el regirse por su ordenamiento jurídico, ocupándose igualmente de la protección de los intereses "iure gestionis" del Estado enviante y prestar los servicios que puedan solicitar nacionales del estado de residencia; procurando siempre mejorar las relaciones mutuas (GómEZ ROBLEDO, 1989:II).

- Como garantía de los derechos humanos: los cónsules también presentan reclamaciones por las violaciones cometidas a partir del Derecho 
Internacional contra los ciudadanos del Estado al que representan, pero estas se presentan por el propio cónsul ante el ente público que cometió la violación. La protección consular es preceptiva en virtud de lo esbozado en los artículos, cinco y treinta y seis de la Convención de Viena de 1963, en los cuales se establece la obligación de los cónsules de prestar asistencia inmediata a sus nacionales y de realizar los esfuerzos necesarios para asegurar la protección de los intereses de las personas migrantes provenientes de sus países; para lo que es requisito sine qua non, poseer la ciudadanía del estado del cónsul que exhibe la reclamación. En procesos de rupturas diplomáticas entre determinados países $\circ$ en situaciones excepcionales, son los cónsules los encargados del tratamiento a sus nacionales; aunque se han cometido violaciones a la asistencia consular por determinados Estados, la jurisprudencia internacional recientemente se ha encargado de ratificar la importancia de ella en sentencias y opiniones consultivas.

- Como función del Estado: En la perspectiva de (FERNÁNDEZ BULTÉ, 2002: P. 56), las funciones son el conjunto de acciones mediante las cuales el aparato de poder estatal intenta perpetuarse, defenderse y reproducirse eficazmente, siendo disímiles sus clasificaciones, pero a los efectos de esta investigación se tomará la expuesta por el autor cubano, que denomina funciones internas, a las que el Estado realiza ad interim de sus fronteras y como funciones externas, las que desarrolla en la Comunidad de Naciones y se manifiestan en los derechos y deberes internacionales, los que se encuentran en estrecha vinculación. Atribuyéndole a los cónsules funciones políticas, de asistencia y protección consular.

A la par de las anteriores y como veníamos comentando la protección consular se ha declarado como derecho humano por la doctrina, pero para ello ha de argumentarse desde la perspectiva técnica jurídica qué son los derechos humanos, en sus rasgos esenciales.

\section{Estudio teórico de los derechos humanos como categoría científica}

Los derechos son "el conjunto de valores éticos, culturales, sociales, económicos y jurídicos que por consenso de la comunidad de naciones, constituyen los ideales correspondientes a una etapa dada de desarrollo histórico y a ese fin se han consagrado en documentos jurídicos, es el conjunto de facultades, instituciones y prerrogativas que en cada momento histórico concretan las exigencias de la dignidad, la libertad y la igualdad humana, las cuales deben ser reconocidas positivamente por los ordenamientos jurídicos" (PÉREZ LUÑo, 1993: 25).

En este comentario se realizan algunas valoraciones, tomando como referente metodológico, la clasificación de los "derechos", que generalmente se clasifican en derechos civiles, económicos, sociales, culturales, derechos de la solidaridad, 
derechos políticos; téngase en cuenta que la clasificación de los derechos no significa la jerarquización de unos y otros.

Los derechos humanos tienen como rasgo fundamental su carácter progresivo e irreversible, lo que significa que obedecen a un iter evolutivo en su formación y no es un catálogo cerrado. Una vez otorgado los siguientes derechos, son irrevocables, su interdependencia no es más que la complementación entre ellos y no la jerarquización de unos y otros. La conferencia de Teherán en 1968 y la Asamblea General de 1977, le dieron la misma jerarquía a todos los derechos, también lo hizo la Carta Africana de 198I(Tamayo Salmorán, 1987: 45).

Son universales "para todos los hombres", entendiendo el término en el sentido de que todos ellos son poseídos por todos los individuos, lo cual quiere decir que entre las personas se da una estricta igualdad jurídica básica, referida a los derechos. Otras características que en mi opinión refuerzan la universalidad de los derechos son:

La irrestringibilidad, o sea, cuentan con determinados requisitos como la estricta necesidad de orden público, con una proporcionalidad existente entre el límite del derecho y la causa para restringir los derechos, la publicidad, resulta otro elemento para asegurarse de que la restricción no lacere la dignidad humana, ni la seguridad jurídica. Además, los derechos son imprescriptibles, es decir, no les afecta la prescripción, sin que, por tanto, se adquieran ni pierdan por el simple transcurso del tiempo. Además en la Constitucionalidad de los derechos está la razón de su no restricción. La eficacia directa $\circ$ vinculante $y$ las garantías protectoras acompañan a estos también.

A los que puede agregarse, su inaliabilidad, es decir, no transferibles a otro titular, lo que sí es posible, en términos generales, en los demás derechos subjetivos y tienen un carácter transnacional, pues no importa que la persona pertenezcan a una región o país determinado para ser portadora de los mismos. En este sentido los propios Estados no deben vulnerar cualquier derecho humano alegando su poder estatal, sino que ellos mismos se imponen límites en su actuar gubernativo para la defensa mismos.

De esta forma lo plantea el párrafo $1^{\circ}$ de la Declaración de Viena del 25 de junio de 1993 (Tamayo Salmorán, 1987: 46) adoptada por la Conferencia Mundial de los Derechos Humanos que: "Los Estados tiene el deber, sean cuales sean sus sistemas políticos, económicos y culturales, de promover y proteger todos los derechos humanos". La conferencia de Viena estableció que los derechos humanos son universales indivisibles, irreversibles, progresivos e interdependientes y no son numerus clausus. 
De los derechos humanos no son sólo responsables los Estados sino toda la sociedad, el estado no puede generar los órdenes equitativos necesarios para la construcción de los derechos económicos políticos y sociales, la sociedad debe generar las riquezas necesarias para construirlo, el Estado es un ente distribuidor de esta riqueza y con los derechos económicos sociales y culturales realiza una función de nivelación de desequilibrio. Los derechos económicos, sociales y culturales son una obligación exigible del estado, no de la producción de bienes para la satisfacción de esos derechos sino de obtener resultados en el proceso de su creación por parte del conglomerado humano que lo ha conformado precisamente para que cumpla ese objetivo, quien además está obligado a distribuirlos eliminando esos desequilibrios como parte de la designación social que posee.

Para delimitar estructuralmente un derecho ha de quedar claro:

Con respecto a la titularidad (ámbito personal) puede ser genérica, a "todos", sin distinción o específica, a determinado grupo humano. Con respecto al objeto (ámbito material) del derecho, permite distinguir la actividad objeto del derecho, muy vinculado al actuar social protegido por el mismo y permitirá configurar su contenido esencial, que a su vez posee límites intrínsecos y extrínsecos en su ejercicio por parte de sus titulares, los primeros están derivados en la propia naturaleza del derecho, por lo que sus titulares no podrán ejercer el mismo contrario a su propia naturaleza o con intención de dañar a otras personas, hechos que en ocasiones pueden estar, incluso, sancionados penalmente. Con respecto a los límites de carácter extrínseco, éstos se configuran por el interés general y público de la sociedad, determinados usualmente por la moral y el orden públicos, y por la colisión con los derechos de otras personas.

Una vez abordados los elementos anteriores que dimensionan los derechos, no puede obviarse que la consagración de los derechos fundamentales significa una condición necesaria e inicial para su ulterior disfrute, pero la experiencia histórica ha demostrado que no es suficiente para su efectivo ejercicio y respeto posteriormente. Lo anterior, no evita el que sus titulares, en ocasión de ejercerlos, pueden apreciarlos disminuidos, amenazados o vulnerados, bien por el Estado o por los particulares. Ante tales supuestos, se torna imprescindible dotarlos de las garantías necesarias para el ejercicio real del derecho y para su defensa jurídica en caso que sean vulnerados (PÉrEZ LUÑO, 1993: 46).

Las garantías se comportan como medios que las Leyes Fundamentales y la Comunidad Internacional, ponen a disposición de las personas para sostener y defender sus derechos frente a las autoridades, los individuos y los grupos sociales y sin las cuales, el reconocimiento de estos últimos será un simple catálogo de buenas intenciones (FIX ZAMUDIO, 1982:50). 
Obtenidos, los rudimentos necesarios para identificar la presencia de un derecho humano, se analizará la sentencia del 3l de Marzo del 2004 del Tribunal Internacional de Justicia en el Caso Avena, en correspondencia con la Opinión Consultiva n. 16, sobre El Derecho a la Información sobre la Asistencia Consular en el Marco de las Garantías del Debido Proceso Legal (del OI. I0.1999), de la Corte Interamericana de Derechos Humanos, realizada por México ante el mismo caso, para argumentar la protección consular como derecho humano.

\section{La sentencia del 3 I de Marzo del 2004 del Tribunal Internacional de Justicia en el Caso Avena: fundamentos de la protección consular como derecho humano}

HECHOS: Estados Unidos no informo a 52 nacionales mexicanos condenados a muerte de su derecho de ser atendido por su cónsul (Artículo 36.l sobre relaciones consulares de 1963) y no permitieron por aplicación de su derecho penal interno que estas personas invocasen este derecho. México solicito la restitución internacional mediante la anulación o privación por vía de efecto a los veredictos de culpabilidad contra sus nacionales. La Corte insistió en que la reparación adecuada no consistía en la anulación de acusaciones y sentencias sino de promover una revisión que le permitiera a los acusados beneficiarse a su derecho a la asistencia consular. Voto a favor de la adopción de la presente Opinión Consultiva de la Corte Interamericana de Derechos Humanos, que constituye, a mi juicio, un significativo aporte a la evolución del Derecho Internacional de los Derechos Humanos. Hace cuatro años, la Corte Interamericana emitió la histórica Opinión Consultiva n. 16, sobre El Derecho a la Información sobre la Asistencia Consular en el Marco de las Garantías del Debido Proceso Legal (del 01.10.1999), (Corte Interamericana de Derechos Humanos, 2008: 107), verdaderamente pionera, que ha servido de inspiración para la jurisprudencia internacional in statu nascendi sobre la materia, (UNITED NATIONS, 2004: 660).

Como dijera la citada Corte y la referida Opinión Consultiva, la interpretación de toda norma debe hacerse de buena fe, conforme con el sentido corriente que debe atribuirse a los términos empleados por el tratado en cuenta su objeto y fin, como lo establece la Convención de Viena sobre el Derecho de los Tratados y aunque en atención a su naturaleza y a su historia legislativa, la Convención de Viena sobre Relaciones Consulares no tiene por objeto otorgar derechos individuales, los derechos de comunicación y de notificación consular son, sobre todo, derechos estatales, pues la Convención tiene como función reconocer el derecho de los Estados de asistir a sus nacionales a través de los funcionarios consulares.

Lo que para nada obsta, que a su vez tenga la función de reconocer el derecho correlativo del nacional del Estado que envía, de tener acceso al funcionario consular, lo que se colige, a partir del artículo 36 de la Convención de Viena, sin 
hacer distinciones en relación con la situación de dichas personas, del cual se desprenden los derechos de la persona extranjera privada de la libertad a ser informada sobre: primero, su derecho a solicitar y lograr que las autoridades competentes del Estado receptor informen a la oficina consular competente sobre su arresto, detención o puesta en prisión preventiva $y$, segundo, su derecho a dirigir a la oficina consular competente cualquier comunicación, sin dilación.

Del mismo artículo 36, se deducen los elementos que tipifican a la protección como derecho humano:

- Con respecto a la titularidad (ámbito personal), el titular de este derecho es la persona privada de la libertad.

Generando deberes correlativos para los Estados, los funciones de los propios funcionarios consulares, que deben visitar a su nacional que se encuentre arrestado, detenido o en prisión preventiva, a hablar con él y a organizar su defensa ante los tribunales respectivos, visitar a sus nacionales que se encuentren arrestados, detenidos o presos en cumplimiento de una sentencia. No obstante, los funcionarios consulares deben abstenerse de intervenir en favor del nacional privado de la libertad, cuando éste así lo solicite. Así, el Estado puede asistir a la persona en su defensa, nombrando o contratando un abogado, obteniendo pruebas en el país de origen, verificando que tenga una adecuada representación legal y asistiendo al detenido.

- En primer término la Corte dimensiona el derecho a la protección desde la perspectiva consular en:

- El derecho a la notificación consular o derecho a la notificación, es el derecho del nacional del Estado que envía a solicitar y obtener que las autoridades competentes del Estado receptor, informen sin retraso alguno sobre su arresto, detención o puesta en prisión preventiva, a la oficina consular del Estado que envía.

- El derecho de asistencia consular o derecho de asistencia, es el derecho de los funcionarios consulares del Estado que envía a proveer asistencia a su nacional.

- El derecho a la comunicación consular o derecho a la comunicación, es el derecho de los funcionarios consulares y de los nacionales del Estado que envía, a comunicarse libremente. Ahora bien, el Estado que envía es el Estado del cual es nacional la persona privada de libertad. El Estado receptor es, por su parte, el Estado en que se priva de libertad al nacional del Estado que envía.

Al respecto y complementando la sentencia la Corte Interamericana determinó que, el cumplimiento del deber estatal correspondiente al derecho a la comunicación consular, no está sujeto al requisito de protesta previa del Estado 
que envía. De igual forma, indicó que el derecho a la información sobre la asistencia consular, no tiene requisito alguno para su exigibilidad. En cambio, el derecho a la notificación consular está condicionado, únicamente, a la voluntad del individuo interesado. Con respecto al conocimiento por parte del Estado que tiene a la persona privada de la libertad de que se trata de un extranjero, la identificación del imputado es un requisito indispensable para la individualización penal y es un deber del Estado que lo tiene bajo su custodia y debe informar al detenido los derechos que tiene en caso de ser extranjero, al igual que se le informa sobre otros derechos en razón de la privación de su libertad, sin importar la gravedad de la pena aplicable al delito que da lugar a la privación de la libertad. Con respecto al momento en que debe informarse a la persona detenida sobre sus derechos en caso de ser extranjero, la Convención de Viena establece que debe informarse "en el momento del arresto y en todo caso antes de que el detenido rinda cualquier declaración o confesión ante las autoridades".

En nuestra opinión, más que del dimensionamiento de un derecho estamos hablando del tractus del mismo en el actuar de los Estados y definiendo su objeto (ámbito material), o sea, su actividad y contenido esencial, además de los límites intrínsecos y extrínsecos de los mismos. Finalmente, en la citada sentencia y con respecto a las garantías, se ubica la responsabilidad internacional como garantía a este derecho, coincidiendo con la supra citada opinión consultiva, realizada por México a tenor del mismo caso y expone:

"La obligación de respetar y garantizar los derechos humanos, está estrechamente vinculada con el principio de igualdad y no discriminación. De manera que el incumplimiento de esta obligación mediante un tratamiento discriminatorio, genera responsabilidad internacional para el Estado. La Corte subraya que "la obligación general de respetar y garantizar los derechos humanos vincula a los Estados, independientemente de cualquier circunstancia o consideración, inclusive el estatus migratorio de las personas". Una consecuencia de lo anterior es el deber de los Estados de establecer un recurso simple y efectivo al cual tenga acceso toda persona, independientemente de su condición migratoria, para solicitar la protección de sus derechos. Esta es una obligación erga omnes, que se impone a los Estados con respecto a las personas que se encuentran bajo su jurisdicción, independientemente de su condición migratoria. Los Estados tienen la facultad de fijar políticas migratorias y de establecer medidas relacionadas con el control del ingreso, permanencia y salida de las personas de su territorio. Estas medidas deben proteger y garantizar los derechos humanos de toda persona (...). No sólo el ordenamiento jurídico interno debe ser acorde con las obligaciones internacionales de los Estados, sino que los órganos y funcionarios de las tres ramas del poder público deben actuar conforme con estas obligaciones. En síntesis, el Estado no puede subordinar o condicionar la protección y garantía del principio de igualdad ante la ley y de no discriminación, a la consecución de objetivos en sus políticas públicas, inclusive a los objetivos en materia de política migratoria." 
En ese mismo sentido, la Corte Internacional de justicia en la sentencia que se analiza expone, con respecto a la violación del derecho asistencia consular de los mexicanos y mandando al Estado norteamericano a retrotraer al proceso, al expresar que... "Ia conformidad con el Derecho interno y la conformidad con las disposiciones de un tratado son cuestiones diferentes. Lo que constituye violación de un tratado puede ser lícito en Derecho interno y lo que es ilícito en Derecho interno puede no suponer violación alguna de un tratado. No obstante, la regla según la cual la calificación de un comportamiento como ilícito en la esfera internacional no queda afectada por la calificación del mismo hecho como lícito en el Derecho interno, no admite excepción en los casos en que las reglas del Derecho Internacional exigen al Estado que aplique las disposiciones de su Derecho interno, por ejemplo, dando a los extranjeros el mismo trato que a sus nacionales. Cierto es que en tal caso, la aplicación del Derecho interno es pertinente para la cuestión de la responsabilidad internacional, pero ello se debe a que es la misma regla de Derecho Internacional la que la hace pertinente, por ejemplo, incorporando la norma de conformidad con el Derecho interno como norma internacional aplicable como un aspecto de ésta”...

En nuestra opinión, a partir del precedente sentado por esta sentencia y sin desdeñar las peculiaridades de la aplicabilidad y maniqueísmo de las normas internacionales como fuentes del Derecho, la Responsabilidad Internacional, se muestra como garantía de este derecho en el plano internacional al plantear a los Estados la obligación de seguir determinadas reglas de conducta respecto a los extranjeros dentro de su territorio, en el caso de que fueran violadas en circunstancias determinadas y se causa daño a las personas naturales dentro de su territorio se incurre en la responsabilidad que se le pueda exigir por el Estado del que es nacional el mismo, solicitando la correspondiente reparación o resarcimiento del daño.

Completándose así, los elementos que configuran una de las dimensiones de la protección consular, como derecho humano, porque en nuestro juicio es una institución múltiple.

\section{Marco constitucional para desarrollar la atención consular como derecho humano.}

En el año 1976, se promulgó la vigente Constitución de la República de Cuba, en virtud de su carácter territorial, estableció una plataforma para la protección de todos los individuos, que sirvió como referente para interpretar el resto del texto constitucional y del ordenamiento jurídico; compuesta por el Preámbulo, donde constó el apotegma martiano que ordenó la construcción de la República por todos y para el bien de todos; el entonces artículo 4l, que se dedicó a la prohibición de no discriminación de las personas naturales a partir de varios criterios, entre ellos, el origen nacional y el artículo 9 en el cual se fijaron las funciones del Estado, con un número importante de 
prestaciones sociales a favor de todos los individuos que se encontraban en el territorio cubano.

\section{Reflexiones finales}

I. La protección consular teóricamente puede catalogarse como una institución multidimensional es órgano de la Administración Pública, garantía internacional de los derechos humanos, función del Estado y derecho humano.

2. La protección consular es un "derecho humano" a partir de la propia formulación de la Convención de Viena sobre relaciones consulares de 1963 y de la jurisprudencia internacional, especialmente la sentencia 31 de Marzo del 2004 del Tribunal Internacional de Justicia yla Opinión Consultiva n. 16, sobre El Derecho a la Información sobre la Asistencia Consular en el Marco de las Garantías del Debido Proceso Legal (del 0I.10.1999), de la Corte Interamericana de Derechos Humanos, teniendo en cuenta que:

- Titularidad (ámbito personal), el titular de este derecho es la persona privada de la libertad.

\section{- Objeto o contenido esencial:}

- El derecho a la información sobre la asistencia consular, no tiene requisito alguno para su exigibilidad. Con respecto al momento en que debe informarse a la persona detenida sobre sus derechos en caso de ser extranjero, la Convención de Viena establece que debe informarse "en el momento del arresto y en todo caso antes de que el detenido rinda cualquier declaración o confesión ante las autoridades".

- El derecho a la notificación consular o derecho a la notificación, es el derecho del nacional del Estado que envía a solicitar y obtener que las autoridades competentes del Estado receptor, informen sin retraso alguno sobre su arresto, detención o puesta en prisión preventiva, a la oficina consular del Estado que envía. El derecho de asistencia consular o derecho de asistencia, es el derecho de los funcionarios consulares del Estado que envía a proveer asistencia a su nacional. El derecho a la notificación consular está condicionado, únicamente, a la voluntad del individuo interesado.

- El derecho a la comunicación consular o derecho a la comunicación, es el derecho de los funcionarios consulares y de los nacionales del Estado que envía, a comunicarse libremente. Ahora bien, el Estado que envía es el Estado del cual es nacional la persona privada de libertad. El Estado receptor es, por su parte, el Estado en que se priva de libertad al nacional del Estado que envía. El cumplimiento del deber estatal correspondiente al derecho a la comunicación consular, no está sujeto al requisito de protesta previa del Estado que envía. Con respecto al conocimiento por parte del Estado que tiene a la persona privada de la libertad de 
que se trata de un extranjero, la identificación del imputado es un requisito indispensable para la individualización penal y es un deber del Estado que lo tiene bajo su custodia.

- Genera deberes correlativos para los Estados, los funciones de los propios funcionarios consulares, que deben visitar a su nacional que se encuentre arrestado, detenido o en prisión preventiva, a hablar con él y a organizar su defensa ante los tribunales respectivos, visitar a sus nacionales que se encuentren arrestados, detenidos $\circ$ presos en cumplimiento de una sentencia. No obstante, los funcionarios consulares deben abstenerse de intervenir en favor del nacional privado de la libertad, cuando éste así lo solicite. Así, el Estado puede asistir a la persona en su defensa, nombrando o contratando un abogado, obteniendo pruebas en el país de origen, verificando que tenga una adecuada representación legal y asistiendo al detenido.

- Tiene como garantía la responsabilidad internacional, declarada por la experiencia jurisprudencial, aunque pueden utilizarse otros medios de solución de conflictos internacionales.

\section{Lista de Referencias}

Gómez ROBledo, A., Fundadores del Derecho Internacional Público, Instituto de Investigaciones Jurídicas de la UNAM, México d.f, 1989.

Verdross, A., Derecho Internacional Público, 5a edición, Aguilar, Madrid.

MARTÍNEZ, PÉREZ, O.,'La protección diplomática y la responsabilidad jurídica internacional", Revista Contribuciones a las Ciencias Sociales, octubre de 2011 [en línea], disponible en:<http://www.eumed.net/rev/cccss//4/omp.html>, (consultada el 2006.02.25, 3:p.m.)

FERNÁNDEZ Bulté, J., Teoría del Estado y el Derecho. Teoría del Estado...cit, pp. 62 $-74$.

CORREA, O., Acerca de los derechos humanos. Apuntes para un ensayo, Coyoacan S.A., México df, 2003.

AA.VV, Los fundamentos filosóficos de los derechos humanos, Serbal S.A., España, 1985.

Álvarez Conde, E., Curso de Derecho Constitucional, volumen VI, Tecnos S.A., 1992.

PeCes Barba, G., Deberes y Derechos Fundamentales, Centro de Estudios Constitucionales, 1993.

NIKKEN, P., "Sobre el concepto de Derechos Humanos", Revista del Seminario sobre Derechos Humanos, Instituto Interamericano de Derechos Humanos, San José, Costa Rica, 1997.

Pérez LUÑo, E., Derechos Humanos, Estado de Derecho y Constitución, Tecnos, Madrid, 1974.

AA.VV, Teoría del Derecho y Conceptos Dogmáticos, UNAM, México, $1987 .$. 
CORTE INTERAMERICANA DE DERECHOS HumANOS, Fallos y opiniones consultivas,

Serie C, Número I30, Sanabria S.A., San José, 2008.

UNITED NATIONS, The International Legal Materials, XLIII, número 3, mayo 2004.

ASENSI SABATER, J., Constitucionalismo y Derecho Constitucional. Materiales para una introducción, Tirant lo Blanch, Valencia, 1996.

BeCERRA RAMíreZ, M., Derecho Internacional Público, Instituto de Investigaciones Jurídicas de la UNAM, México d.f, 1997.

BLÁZQUEZ RODRíGUEZ, I, Los nacionales de terceros países en la Unión Europea, Servicio de publicaciones, Universidad de Córdoba, Córdoba, 2001.

BLÁZQUEZ RUIZ, J. F.,” Derechos humanos, Inmigración y Discriminación: retos de la integración social", Cuadernos Electrónicos de Filosofia del Derecho, número 5, [en línea], disponible en:<(http://www.uv.es/CEFD)>, (consultada el I I/02/2009, 3:p.m.), 2002.

BobBiO, N., Teoría General del Derecho, 5a. reimpresión, Debate, España, 1998.

BuRDEAU, G., Derecho Constitucional e Instituciones políticas, Nacional, Madrid, España, 1981.

BuRgOA, I., Las garantías individuales, Porrúa, México df, 1954.

BuRguÉs, J. W, Ciencia Política y Derecho Constitucional Comparado, Imprenta San Bernardo, Madrid, 1922.

CANÇADO TRINDADE, A. A., Tratado de Direito Internacional dos Direitos Humanos, tomo III, Fabris $S \wedge$ Dama Alnam $2 n \cap 3$

CARRILLO SALCEDO, J.A. ISSN 1993-4505 / No. 18, 2015 / Martínez Pérez y Zaldivar Valdés Madrid, 1995.

D Estefano PISANI, M., Fundamentos del Derecho Internacional Contemporáneo, André Voisin, La Habana, 1988.

Sociales, La Habana, 2003.

Esquemas de Derecho Internacional Público, tomo I, Pueblo y Educación, La Habana, 1977.

DíEZ DE VELASCO, M., Organismos de Derecho Internacional Público, Tecnos, Madrid, 2000.

Madrid, 2002.

GASTEIZ, V., Curso de Derecho Internacional, Editorial del País Vasco, Bilbao, 1993.

GÓmEZ RoBledo, A., Fundadores del Derecho Internacional Público, Instituto de Investigaciones Jurídicas de la UNAM, México d.f, 1989.

VERDROSS, A., "Règles internationales concernant le traitement des étrangers", Recueil des Courses, tomo 37, Institut do Droit Internacional, La Haya, (I93 IIII).

Derecho Internacional Público, Aguilar, Madrid, 1957.

"La théorique. Classique des droits fundamentaux des Etats, "Recueil des Cours de l'Academie de Droit International, Institut de Droit International, La Haya, 1925. 
